\title{
Determination of the water diffusivity of horticultural substrates: comparison of different approaches for the one-step outflow data analysis
}

\author{
Carlo Bibbiani, ${ }^{1}$ Carlo A. Campiotti, ${ }^{2}$ Luca Incrocci, ${ }^{3}$ Alberto Pardossi ${ }^{3}$ \\ ${ }^{1}$ Department of Veterinary Science, University of Pisa; ${ }^{2}$ Department UTEE-AGR, ENEA, Roma; \\ ${ }^{3}$ Department of Agriculture, Food and Environment Science, University of Pisa, Italy
}

\begin{abstract}
The improved iterative method for the simultaneous determination of the hydraulic properties of growing media from one-step experiment by Bibbiani, was performed on pure peat, pure pumice, and peat/pumice (1peat:1pumice by volume) mix, and compared with simplified equations by Valiantzas and Londra, who set up a new two-point method for calculating the water diffusivity, and with Van GenuchtenMualem model. Brooks and Corey equations for water retention and hydraulic conductivity characterized the hydraulic properties of the porous media in relation to the iterative procedure. In the present work, the estimated water retention curves are compared with nine experimental data, and with the estimation of the Van GenuchtenMualem model, via the RETC code, taking into account retention and diffusivity data. Bibbiani's and Van Genuchten-Mualem's estimations overlap except for the very wet range near saturation $\left(\mathrm{R}^{2}\right.$ equals to 0.9997, 0.9999, 0.9998 for pure pumice, 1peat:1pumice mix, and pure peat respectively, for Bibbiani's estimation; $R^{2}$ equals to 0.9923, 0.9541, 0.9993 for pure pumice, 1peat:1pumice mix, and pure peat respectively, for Van Genuchten-Mualem's estimation), whereas the Valiantzas and Londra's procedure didn't get satisfactory results, apparently because of different requirements related to the final pressure head applied in one-step experiment. In regard to diffusivity, a good similarity between Bibbiani's and Van Genuchten-Mualem's curves can be assessed, being the mean ratio values of the $D(\theta)$ from Valiantzas equation divided by $D(\theta)$ from Bibbiani equation equal to $1.20,1.10$,
\end{abstract}

\footnotetext{
Correspondence: Carlo Bibbiani, Department of Veterinary Sciences, University of Pisa, viale delle Piagge 2, 56124 Pisa, Italy.

Tel.+39.050.2216813 - Fax: +39.050 .2216706 .

E-mail: carlo.bibbiani@unipi.it

Contributions: the authors contributed equally.
}

Key words: hydraulic characteristics of substrates, one-step experiment, parameter estimation.

Received for publication: 25 October 2013

Accepted for publication: 7 January 2014.

(C) Copyright C. Bibbiani et al., 2013

Licensee PAGEPress, Italy

Journal of Agricultural Engineering 2013; XLIV:219

doi:10.4081/jae.2013.219

This article is distributed under the terms of the Creative Commons Attribution Noncommercial License (by-nc 3.0) which permits any noncommercial use, distribution, and reproduction in any medium, provided the original author(s) and source are credited. and 1.31 for pure pumice, 1peat:1pumice mix, and pure peat respectively, while Valiantzas and Londra's procedure generally results in higher values. Due to the lack of estimation of the water retention curve, Valiantzas and Londra's procedure fails to estimate the hydraulic conductivity function, whereas Bibbiani's and Van Genuchten-Mualem's curves match together in most cases.

\section{Introduction}

Water flow and solute transport modelling must rely on the knowledge of water retention and hydraulic conductivity curves, namely $\theta(h)$ and $K(\theta)$ or $K(h)$. Computed water balances are very sensitive to soil hydraulic parameters and therefore their accurate determination is essential (Jhorar et al., 2004; Schneider et al., 2009). Experimental methods have been set for this task, with varying complexity and accuracy of measurements. The substrate moisture retention curve is rather easily achieved. On the contrary, the determination of the hydraulic conductivity function requires the establishment of steadystate moisture profiles under unsaturated conditions, which is a tough assignment. This difficulty led scientists to conceptual models that could predict $K(\theta)$ from the moisture retention curve coupled by $K s$ measured independently (conductivity at saturation, where simple permeameters have been manufactured either constant head or falling head). Gardner (1962) introduced another method which relies on the determination of diffusivity $\mathrm{D}(\theta)$ relationship with one-step outflow data, being diffusivity the ratio of conductivity to the specific water capacity $\mathrm{C}(\mathrm{h})=\mathrm{d} q / \mathrm{dh}$. Henceforth, many authors developed more accurate equations.

In this paper the cumulative outflow data obtained by one-step outflow experiment are used for the prediction of $D(\theta)$ employing equations from Valiatzas (1989), Bibbiani (2002), Valiantzas et al. (2007), Valiantzas and Londra (2012), and Van Genuchten-Mualem model (Mualem, 1976; Van Genuchten, 1980). Bibbiani's method, assuming a particular power form with a small number of parameters for the $\theta(h)$ and $\mathrm{K}(\mathrm{h})$ curves, leads to the estimation of the hydraulic characteristics, as well as the Van Genuchten-Mualem model.

\section{Materials and methods}

Five replications of peat, pumice, and a peat/pumice (1Pe:1Pu) [1:1 $(\mathrm{v} / \mathrm{v})]$ mix were packed in $347.5 \mathrm{~mL}$ cylindrical aluminum tubes (7.6 $\mathrm{cm}$ in diameter, $7.6 \mathrm{~cm}$ in height). The pumice is a tout-venant material sieved at $8 \mathrm{~mm}$ maximum particle size. At the end of the packing procedure described by Bibbiani (2002), the substrate samples were subjected to the one-step procedure. An initial pressure equal to $-1 \mathrm{kPa}$ referred to the core centre was applied; once equilibrium was reached, a sudden application of a positive gas pressure increment marked the 
initiation of the outflow process recorded with time until equilibrium at the new pressure. Final pressure at $-10 \mathrm{kPa}$ has been chosen as the most suitable (Bibbiani, 2002). A duration of $48 \mathrm{~h}$ proved to be sufficient to allow for the necessary equilibrium and calculations. The above samples were re-saturated and a drying retention curve determined, along with other hydraulic parameters such as saturated hydraulic conductivity Ks, total porosity $\theta_{\mathrm{TP}}$, free-drainage water content $\theta_{\mathrm{fd}}$.

In order to calculate $\mathrm{D}(\theta)$ function, Valiantzas (1989) derived an accurate equation, starting from Gardner (1962) and Passioura (1976) approximate equations, as:

$$
\mathrm{D}(\theta)=-\frac{2 \cdot L^{2}}{\pi^{2}}\left(\frac{d q}{d \theta}+\frac{q}{\theta-\theta_{f}}\right)
$$

where $\mathrm{q}=d \theta / d t$ is the outflow rate, $\theta_{\mathrm{f}}$ is the final volumetric water content in one-step experiment, and $\mathrm{L}$ is the height of the sample. Valiantzas et al. (1988), and Valiantzas and Kerkides (1990) proposed a simple method for the simultaneous determination of hydraulic properties starting from an estimation of diffusivity function $\mathrm{D}(\theta)$. Bibbiani (2002), in order to remove the limitation due to the absence of the $\theta r$ parameter, re-introduced the latter in the relative water content $\Theta$ equation. Thus, the proposed equations are written as: i) Brooks and Corey's (B\&C, as referred herein after), for water retention

$$
\begin{array}{ll}
\Theta=\left[\frac{H e}{h}\right]^{\lambda} & \mathrm{h}>\mathrm{He} \\
\Theta=\frac{\theta-\theta x}{\theta-\theta t}=1 & 0 \leq \mathrm{h} \leq \mathrm{He}
\end{array}
$$

ii) and for conductivity

$$
\operatorname{Kr}(\Theta)=\frac{K(\Theta)}{K_{S}}=(\Theta)^{\mathrm{p}}
$$

where $\theta s$ is the saturated water content, $\theta r$ is the residual water content, He is the air-entry value, $\mathrm{p}$ and $\lambda$ are fitting parameters (see Table 1 for units).

Eq. (2), (3), and (4) can be substituted for $\mathrm{D}(\Theta)$ equation obtaining:

$$
\mathrm{D}(\Theta)=\mathrm{B} \cdot(\Theta)^{\mathrm{A}}
$$

$$
\begin{aligned}
& \mathrm{B}=\frac{\mathrm{Ks} H \mathrm{He}}{\lambda \cdot(\theta \mathrm{s}-\theta \mathrm{r})} \\
& \mathrm{A}=\mathrm{p}-1-\frac{1}{\lambda}
\end{aligned}
$$

The problem appears as an identification problem of parameters A, $\mathrm{B}, \lambda$, and $\theta \mathrm{r}$, while $\theta \mathrm{s}$ is taken as a known parameter, and calculated in this paper as:

$$
\theta_{\mathrm{S}}=\frac{3 \theta_{T P}+\theta_{\mathrm{fd}}}{4}
$$

The outflow rate $\mathrm{q}(\theta(\mathrm{t}))$ is related to diffusivity $\mathrm{D}(\theta)$ by approximate analytical expressions, $\lambda(\mu)$ and $\theta_{\mathrm{L}}(\mu), \mu$ depending on $(\theta ; \theta$ r; A), as proposed by Valiantzas and Kerkides (1990) and modified by Bibbiani (2002):

$$
q(\theta)=\frac{B \cdot \lambda *(\mu)}{(A+1) L^{2}\left(\theta_{S}-\theta t\right)^{A}} \cdot\left[\left(\theta_{L}(\mu)^{-\theta r}\right)^{A+1}-(\theta f-\theta r)^{A+1}\right](9)
$$

Each $\theta r$ value leads to estimate parameters A and B minimizing the difference between simulated and measured outflow rates $q(\mathrm{t})$. Consequently the $D(\theta)$ function is calculated. Then, the unknown parameter $\lambda$ is estimated minimizing the $S(\theta r, \lambda)$ objective function, which is the difference between the natural logarithm of measured and simulated relative water content data, calculated as:

$$
\mathrm{S}(\theta \mathrm{r}, \lambda)=\sum_{\mathrm{y}=1}^{\mathrm{M}}\left\{\ln \left[\frac{\theta y-\theta t}{\theta \mathrm{s}-\theta \mathrm{t}}\right]-\lambda \cdot \ln \left[\frac{\lambda(\theta \mathrm{s}-\theta t)}{\mathrm{Ks}} \mathrm{B}_{(\theta) \mathrm{c}}\right]+\lambda \cdot \ln \left[\mathrm{h}_{\mathrm{y}}\right]\right\}^{2}
$$

where $M$ means number of experimental $\theta(\mathrm{h})$ data, $\theta_{\mathrm{y}}$ is the water content in correspondence with $\mathrm{h}_{\mathrm{y}}$ value of matric potential.

Thus, the minimum value function $S(\theta r, \lambda)$ can be plotted, and its minimum singles out the best fitting vector $\left[\bar{\theta}_{\mathrm{r}}, \bar{\lambda}\right]$. Eq. (6) and (7) give parameters He and p, and so functions $\theta(\mathrm{h})$ and $\mathrm{K}(\mathrm{h})$ are plotted. In order to neglect the porous plate impedance effect on the results, which might be significant at the early stages of the outflow process, Valiantzas et al. (1988) forced the procedure for estimating $\mathrm{D}(\theta)$ analysing only the part of the curve where the cumulative outflow $\mathrm{V}$ ceases to be linear with respect to the square root of time $\sqrt{t}$. Later on, Valiantzas et al. (2007) and Valiantzas and Londra (2012) (V\&L, as

Table 1. List of symbols.

\begin{tabular}{lccccc}
\hline Variable & Description & Units & Variable & Description \\
\hline$\theta_{\mathrm{TP}}$ & Total porosity & $\mathrm{m}^{3} \mathrm{~m}^{-3}$ & $\lambda, \mathrm{p}$ & Eq. (2), (4) B\&C parameters \\
$\theta_{\mathrm{s}}$ & Saturated water content & $\mathrm{m}^{3} \mathrm{~m}^{-3}$ & $\mathrm{~L}$ & Core height \\
\hline$\theta_{\mathrm{fd}}$ & Free-drainage water content & $\mathrm{m}^{3} \mathrm{~m}^{-3}$ & $\mathrm{He}$ & Air-entry value \\
$\theta_{\mathrm{i}}$ & Initial water content & $\mathrm{m}^{3} \mathrm{~m}^{-3}$ & $\mathrm{~A}, \mathrm{~B}$ & $\mathrm{Eq}$ ( (9) parameters \\
\hline$\theta_{\mathrm{f}}$ & Final water content & $\mathrm{m}^{3} \mathrm{~m}^{-3}$ & $\mathrm{~F}, \mathrm{G}$ & $\mathrm{Eq}$. (12) V\&L parameters \\
$\theta_{\mathrm{r}}$ & Residual water content & $\mathrm{m}^{3} \mathrm{~m}^{-3}$ & $\alpha, \mathrm{m}, \mathrm{n}$ & Eq. (13), (15) VG-M parameters \\
\hline$\theta_{\mathrm{y}}$ & Water content at $h_{y}$ matric potential & $\mathrm{m}^{3} \mathrm{~m}^{-3}$ & $\mathrm{Ks}$ & Saturated hydraulic conductivity & - \\
$\mathrm{h}$ & Matric potential & $\mathrm{Pa}$ & $\mathrm{Kr}(\Theta)$ & Relativehydraulic conductivity
\end{tabular}

B\&C, Brooks and Corey; V\&L, Valiantzas and Londra; VG-M, Van Genuchten-Mualem. 
referred herein after) derived some simplified equation for the determination of the hydraulic properties of horticultural substrates, applying respectively Eq. (1) in the former, and B\&C equation and Burdine model (Burdine, 1953) in the latter; they introduced in Eq. (1) a new dimensionless variable obtained from the outflow data as well, the fraction of the remaining outflow water volume $S_{\text {out }}$, as:

$$
\mathrm{S}_{\text {out }}=\frac{\theta-\theta_{\mathrm{f}}}{\theta_{\mathrm{i}}-\theta_{\mathrm{f}}}=\mathrm{F} \cdot(\sqrt{\mathrm{t}})^{\mathrm{G}}
$$

which is related to cumulative outflow $\mathrm{V} v$ s the square root of time $\sqrt{\mathrm{t}}$ with a power form similar to that of Eq. (5), where $\theta_{\mathrm{i}}$ and $\theta_{\mathrm{f}}$ are respectively the initial and final volumetric water content in one-step experiment, $\mathrm{F}$ and $\mathrm{G}$ are fitting parameters. In this context, they derived the following V\&L equation:

$$
\mathrm{D}(\theta)=-\frac{2 \cdot(G-1) \cdot L^{2} \cdot F^{2} / G}{\pi^{2}}\left(\frac{\theta-\theta f}{\theta i-\theta f}\right)^{-2 / G}
$$

In order to evaluate the hydraulic functions, they proposed to measure experimentally the water retention, or alternatively, in their latter paper, to run the one-step procedure fixing $\theta_{\mathrm{f}}$ as close as possible to the real $\theta_{\mathrm{r}}$ value. In the present paper, in order to compare all the previous estimated water retention and hydraulic conductivity curves, the Van Genuchten-Mualem (VG-M, as referred herein after) combined model (Mualem, 1976; Van Genuchten, 1980) was applied to experimental retention data, having fixed their parameters respectively as $m=1-1 / n$, $1=0.5$, and $\theta$ s from Eq. (8). The fitting program RETC (Van Genuchten et al., 1991) estimated $\theta r, \alpha$, and $n$ unknown parameters, computing both experimental retention data coming only from one-step experiment and diffusivity data calculated by Eq. (5).

$$
\begin{aligned}
& \Theta(h)=\frac{\theta-\theta r}{\theta s-\theta r}=\left[1+(\alpha \cdot|h|)^{n}\right]^{-m} \\
& \mathrm{C}(\Theta)=\alpha n m\left(\theta_{s}-\theta_{r}\right) \Theta^{1 / \mathrm{m}}\left(1-\Theta^{1 / \mathrm{m}}\right)^{\mathrm{m}} \\
& \mathrm{K}(\Theta)=\mathrm{Ks} \cdot \Theta^{1 / 2}\left[1-\left(1-\Theta^{1 / m}\right)^{m}\right]^{2} \\
& \mathrm{D}(\theta)=\frac{K(\Theta)}{C(\Theta)}
\end{aligned}
$$

Finally, RETC code estimated the diffusivity $\mathrm{D}(\theta)$ taking as input only 9 experimental moisture retention data, and the other hydraulic functions as well, thus resulting in the VG-M (retention only) curves.

\section{Results and discussion}

Table 1 shows the list of symbols applied in equations and units. Table 2 reports all the measured moisture retention points for the three substrates, and the initial and final pressure heads set-up for one-step experiment. Table 3 shows the estimated parameters for Eq. (2) and (5), as related to the $\mathrm{B} \& \mathrm{C}$ model improved by Bibbiani (2002).

Table 4 refers to Eq. (12), giving parameters of the new dimension- less variable $S_{\text {out, }}$ obtained by Valiantzas et al. (2007). Moreover, it reports the estimation by RETC code for the VG-M model related to Eq. (13), with the analysis of 9 retention data only (derived from independent measurements), and both retention and diffusivity data derived from one-step experiment. A comparison of diffusivity functions, $D(\theta)$, can be carried on applying the estimated parameters (Table 3 and Table 4) to the above discussed equations, and plotting the so-calculated curves, as shown in Figure 1. Irrespective to the substrate nature, there

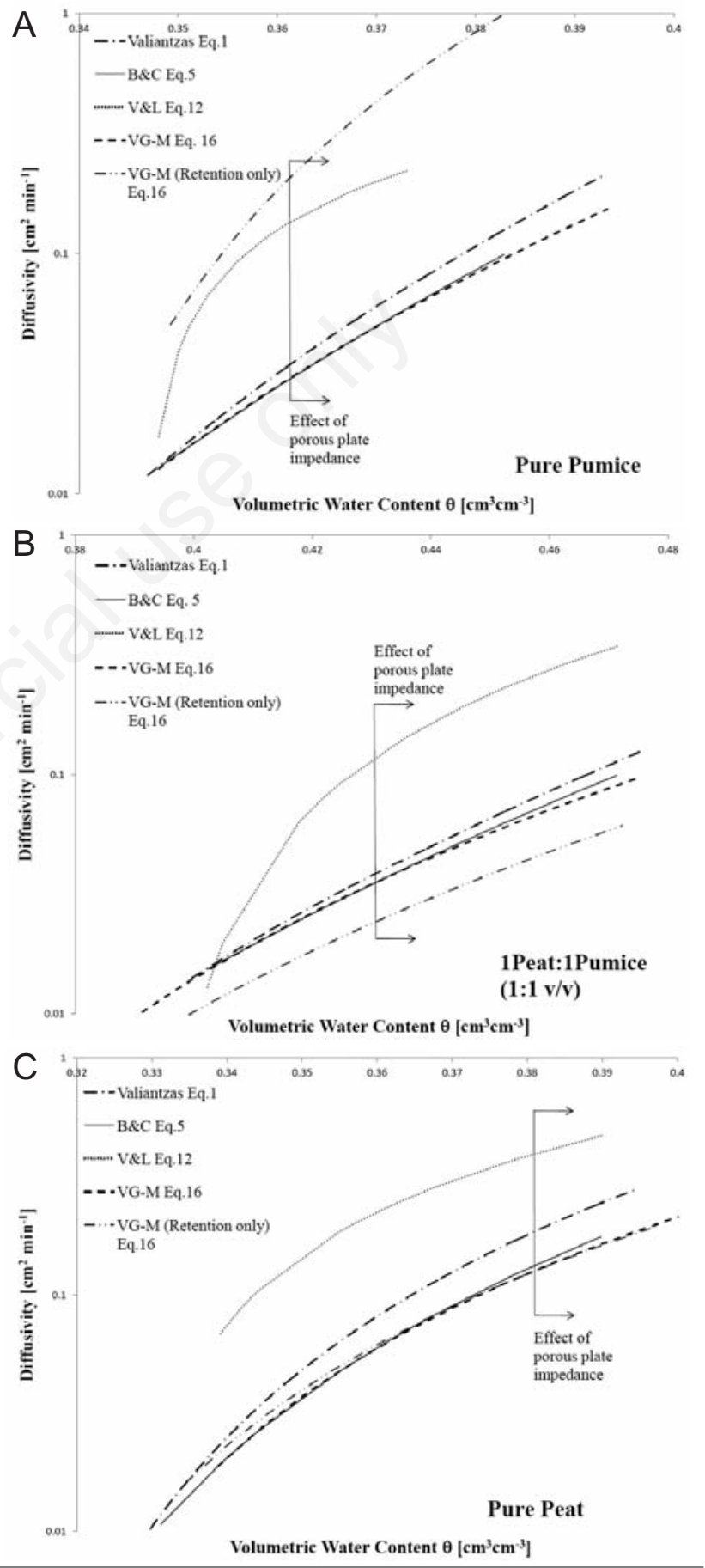

Figure 1. Substrate water diffusivity as a function of volumetric water content, $D(\theta)$, estimated by different equations. A) Pure pumice; B) 1 peat: 1 pumice $(1: 1 \mathrm{v} / \mathrm{v})$; C) pure peat. The short vertical line labeled Effect of the porous plate impedance defines the region where the plate impedance is not negligible. 
is a good agreement between the direct calculation of $\mathrm{D}(\theta)$ from Eq. (1), and both the B\&C model by Eq. (5) and the VG-M model from Eq. (16) (retention and diffusivity data), being the mean ratio values of the $\mathrm{D}(\theta)$ from Eq. (1) divided by $\mathrm{D}(\theta)$ from Eq. (5) equal to $1.20,1.10$, and 1.31 for pure pumice, 1peat:1pumice mix, and pure peat respectively. VG-M model by Eq. (16) shows similar mean ratio values.
In contrast, the VG-M (retention only) curve shows a variable and unpredictable behaviour, suggesting a non-reliable estimation based only on retention data, being the mean ratio values of the $D(\theta)$ from Eq. (1) divided by $\mathrm{D}(\theta)$ from Eq. (16) (retention only) equal to 2.10 , 0.95 , and 1.29 for pure pumice, 1peat:1pumice mix, and pure peat respectively. No explanation of the different performance of this model

Table 2. Water retention data sets and one-step pressure heads set-up.

\begin{tabular}{|c|c|c|c|c|c|}
\hline $\begin{array}{l}\text { Pure peat } \\
\text { Pressure } \\
\text { Head h } \\
{[\mathrm{hPa}]}\end{array}$ & $\begin{array}{c}\text { Water } \\
\text { Content } \theta \\
{\left[\mathrm{m}^{3} \mathrm{~m}^{-3}\right]}\end{array}$ & $\begin{array}{c}\text { 1peat:1pumice } \\
\text { Pressure } \\
\text { Head h } \\
{[\mathrm{hPa}]}\end{array}$ & $\begin{array}{c}\text { Water } \\
\text { Content } \theta \\
{\left[\mathrm{m}^{3} \mathrm{~m}^{-3}\right]}\end{array}$ & $\begin{array}{c}\text { Pure pumice } \\
\text { Pressure } \\
\text { Head h } \\
{[\mathrm{hPa}]}\end{array}$ & $\begin{array}{c}\text { Water } \\
\text { Content } \theta \\
{\left[\mathrm{m}^{3} \mathrm{~m}^{-3}\right]}\end{array}$ \\
\hline $3.8==^{\prime} \theta_{\mathrm{fd}}{ }^{\prime}$ & 0.879 & $3.8==^{\prime} \theta_{\mathrm{fd}}{ }^{\prime}$ & 0.729 & $3.8==^{\prime} \theta_{\text {fdd }}$ & 0.465 \\
\hline $10==^{\prime} \theta_{i}^{\prime}$ & 0.713 & $14==^{\prime} \theta_{i}^{\prime}$ & 0.574 & $10={ }^{\prime} \theta_{i}^{\prime}$ & 0.393 \\
\hline 20 & 0.501 & 20 & 0.525 & 20 & 0.380 \\
\hline 30 & 0.435 & 34 & 0.471 & 30 & 0.370 \\
\hline 50 & 0.379 & 50 & 0.447 & 50 & 0.364 \\
\hline $104={ }^{\prime} \theta_{\mathrm{f}}^{\prime}$ & 0.329 & $104==^{\prime} \theta_{\mathrm{f}}^{\prime}$ & 0.395 & $100={ }^{\prime} \theta_{\mathrm{f}}^{\prime}$ & 0.347 \\
\hline 140 & 0.318 & 147 & 0.376 & 140 & 0.340 \\
\hline 230 & 0.309 & 233 & 0.361 & 230 & 0.335 \\
\hline
\end{tabular}

Table 3. Measures parameters at saturation, and parameter estimation obtained for Eq. (2), (3), (4), (5), (6) and (7). B\&C model.

\begin{tabular}{|c|c|c|c|c|c|c|c|c|}
\hline Substrate & $\begin{array}{c}\rho \\
\mathrm{kg}^{-3}\end{array}$ & $\begin{array}{c}\theta_{\mathrm{TP}} \\
\mathrm{m}^{3} \mathrm{~m}^{-3}\end{array}$ & $\begin{array}{c}\text { Os } \\
\mathrm{m}^{3} \mathrm{~m}^{-3}\end{array}$ & $\frac{\mathrm{Ks}}{\mathrm{cm}^{\mathrm{min}}{ }^{-1}}$ & $\begin{array}{c}\overline{\theta_{r}} \\
m^{3} m^{-3}\end{array}$ & $\mathrm{~A}\left(\bar{\theta}_{\mathrm{r}}, \bar{\lambda}\right)$ & $\begin{array}{c}\mathbf{B}\left(\bar{\theta}_{t}, \bar{\lambda}\right) \\
-\end{array}$ & $\begin{array}{l}\bar{\lambda} \\
-\end{array}$ \\
\hline Peat & 115 & 0.94 & 0.92 & 3.360 & 0.298 & 2.7498 & 33.8752 & 1.1285 \\
\hline 1Pe:1Pu & 307 & 0.86 & 0.83 & 1.44 & 0.206 & 6.1897 & 19.715 & 0.3315 \\
\hline Pumice & 830 & 0.68 & 0.62 & 180.0 & 0.248 & 6.827 & 100.75 & 0.1665 \\
\hline
\end{tabular}

$\mathrm{R}^{2}$ values equal to $0.9998,0.9999,0.9997$ for pure peat, peat/pumice (1Pe:1Pu) mix, and pure pumice respectively.

Table 4. Parameter estimation obtained for Eq. (12). Nonlinear least-squares analysis by RETC program (1=0.5). Fit of 9 experimental retention data only for Eq. (13) Van Genuchten-Mualem VG-M (retention only) model. Simultaneous fit of retention and diffusivity data from one-step experiment for Eq. (13) VG-M model.

\begin{tabular}{|c|c|c|c|c|c|c|}
\hline Variable & $\begin{array}{c}\text { Pure peal } \\
\text { Value }\end{array}$ & St.dev. & $\begin{array}{l}\text { 1peat:1pur } \\
\text { Value }\end{array}$ & SD & $\begin{array}{l}\text { Pure pum } \\
\text { Value }\end{array}$ & St.dev. \\
\hline \multicolumn{7}{|c|}{ Parameter for Eq. (12) } \\
\hline $\mathrm{F}$ & 6.793 & & 10.13 & & 324.2 & \\
\hline G & -1.767 & & -1.433 & & -2.439 & \\
\hline \multicolumn{7}{|c|}{ Fit of 9 experimental retention data only for Eq. (13) } \\
\hline$\theta_{\mathrm{r}}$ & 0.3030 & 0.0058 & 0.2907 & 0.0102 & 0.3283 & 0.0091 \\
\hline$\alpha$ & 0.1042 & 0.0030 & 0.2348 & 0.0113 & 0.8385 & 0.2135 \\
\hline $\mathrm{n}$ & 2.3396 & 0.0700 & 1.5093 & 0.0298 & 1.6297 & 0.1234 \\
\hline $\mathrm{m}$ & 0.5725 & & 0.3374 & & 0.3864 & \\
\hline $\mathrm{R}^{2}$ & 0.9993 & & 0.9995 & & 0.9964 & \\
\hline \multicolumn{7}{|c|}{ Simultaneous fit of retention and diffusivity data from one-step experiment. Eq. (13). } \\
\hline$\theta_{\mathrm{r}}$ & 0.3072 & 0.0007 & 0.3069 & 0.0074 & 0.2788 & 0.0040 \\
\hline$\alpha$ & 0.0984 & 0.0015 & 0.7149 & 0.0782 & 2.7400 & 0.1434 \\
\hline $\mathrm{n}$ & 2.3681 & 0.0244 & 1.3873 & 0.0221 & 1.2906 & 0.0093 \\
\hline $\mathrm{m}$ & 0.5777 & & 0.2792 & & 0.2252 & \\
\hline$R^{2}$ & 0.9993 & & 0.9541 & & 0.9923 & \\
\hline
\end{tabular}



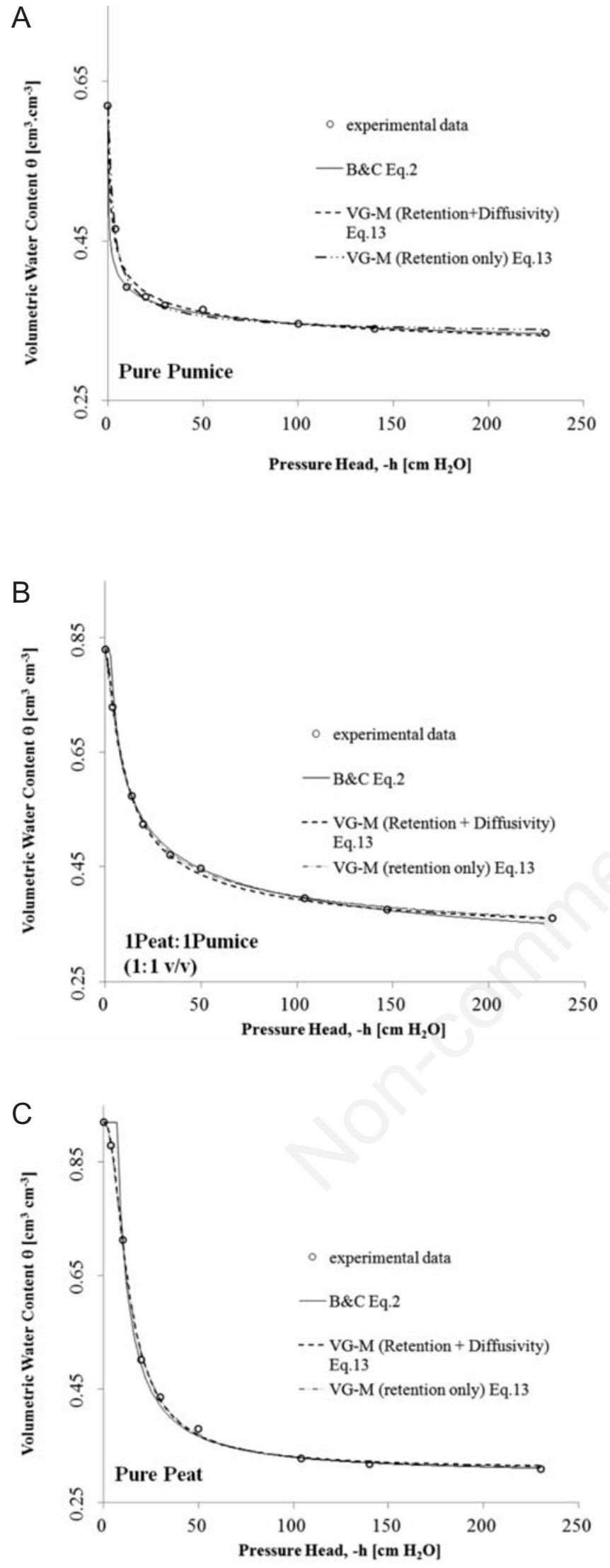

Figure 2. Substrate water retention $\boldsymbol{\theta}(\mathrm{h})$ as a function of pressure head $-h$, measured and estimated by $B \& C$ and VG-M equations. A) Pure pumice; B) 1 peat:1 pumice $(1: 1 \mathrm{v} / \mathrm{v})$; C) pure peat. with the different characteristics of the substrates was found.

The prediction of $\mathrm{D}(\theta)$ by Eq. (12) doesn't match any other ones in this experiment, being the mean ratio values of the $\mathrm{D}(\theta)$ from $\mathrm{Eq}$. (12) divided by $\mathrm{D}(\theta)$ from Eq. (1) equal to $0.63,5.22$, and 1.13 for pure pumice, 1peat:1pumice mix, and pure peat respectively. Since Valiantzas et al. (2007) reported a substantial identity between their estimation and Eq. (1), the huge discrepancy in the present work might depend on the different final pressure at the end of the outflow procedure $\mathrm{h}\left(\theta_{\mathrm{f}}\right)$ that they fixed in the range $-14 \div 18 \mathrm{kPa}$. Doing this way, they assumed that $\mathrm{q}_{\mathrm{f}}$ is very close to the $\mathrm{q}_{\mathrm{r}}$ value, thus letting the estimation of the first iterative value for $\theta_{\mathrm{r}}^{0}$; on the contrary, in this paper, the final pressure head $h\left(\theta_{\mathrm{f}}\right)$ was chosen by analogy to the well-known tension range for the calculation of the hydraulic properties of horticultural substrates, such as the easy available water value.

On the basis of these results, the comparison of the water retention function gives us a deeper understanding of the whole estimation capability. Figure 2 shows the experimental data, the B\&C and VG-M plot of the function, as well. As one can see, the main difference between B\&C Eq. (2) and VG-M Eq. (13) estimated curves lies in the very wet range (i.e. $\mathrm{h}(\theta)<-1 \mathrm{kPa}$ ), being all the rest almost overlapped. The correlation coefficient $\mathrm{R}^{2}$ equals to $0.9997,0.9999,0.9998$ for pure pumice, 1peat:1pumice mix, and pure peat respectively, for B\&C estimation; $R^{2}$ equals to $0.9923,0.9541,0.9993$ for pure pumice, 1peat:1pumice mix, and pure peat respectively, for VG-M estimation. Both the predictions by Valiantzas et al. (2007) and Valiantzas and Londra (2012) don't match the experimental water retention results (data not shown), most likely because of the same reason above explained. Moreover, the B\&C Eq. (2) model, related only to one-step procedure, seems to have the same power of estimation of the VG Eq. (13) model, both of them being in optimal agreement with the experimental water retention data.

Figure 3 provides us information about the sensitivity of Eq. (16) calculating $K(\theta)$ as unknown variable. In fact, despite the large difference between the estimation of $\mathrm{D}(\theta)$ with VG-M (retention and diffusivity data) and VG-M (retention only) curve by Eq. (15), the influence of the specific water capacity $\mathrm{C}(\mathrm{h})$, being the first derivative of the $\theta(\mathrm{h})$ curve, results in a much narrow gap between the respective $K(\theta)$ curves. In fact, except for the VG-M (retention only) model applied to Pure Pumice, which leads to a remarkable discrepancy in the wet range, the estimated functions are close to each other, relatively to each substrate. In this respect, the RETC code computation of experimental data coming only from one-step procedure provides a sound basis comparison with the improved iterative method by Bibbiani (2002): the mean ratio values of the $K(\theta)$ from Eq. (4) divided by $K(\theta)$ from Eq. (16) (retention and diffusivity data) equal to $0.92,1.52$, and 1.11 for pure pumice, 1peat:1pumice mix, and pure peat respectively.

\section{Conclusions}

This study aims to compare different methods for the simultaneous determination of the hydraulic properties of growing media from onestep experiment, exploiting the capability of the latter procedure to estimate the diffusivity function. Valiantzas et al. (1988, 2007), Valiantzas and Kerkides (1990) and Valiantzas and Londra (2012) set up attractive equations for this task. From their approach stems the Bibbiani (2002) improvement of the estimation method, based on Brooks and Corey equations for hydraulic functions. An independent set of 9-water retention experimental data allows the comparison of estimated curves. Moreover, the RETC software with the Van Genuchten-Mualem model is performed, resulting in other two estimations of the hydraulic function: the first one coming only from water retention experimental data, the second one computing reten- 


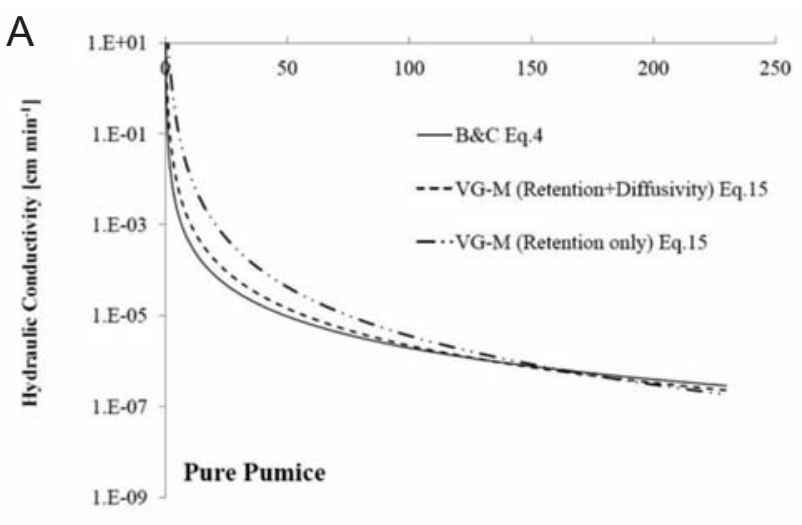

Pressure Head, -h $\left[\mathrm{cm} \mathrm{H} \mathrm{H}_{2} \mathrm{O}\right]$
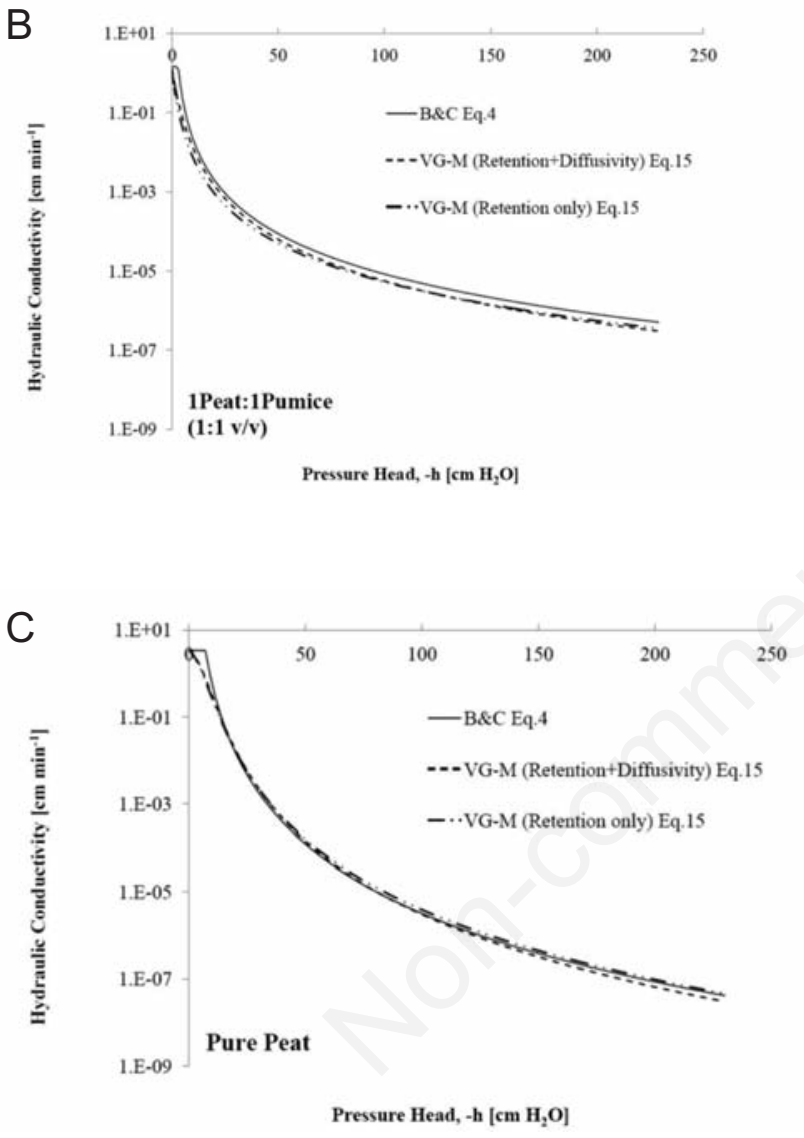

Figure 3. Substrate water conductivity $\mathrm{K}(\mathrm{h})$ as a function of pressure head $-h$, estimated by different equations. A) Pure pumice; B) 1 peat:1 pumice $(1: 1 \mathrm{v} / \mathrm{v})$; C) pure peat. tion and diffusivity data from one-step experiment.

Due to different requirements related to the final pressure head applied in one-step experiment, Bibbiani's method leads to a good estimation of hydraulic functions for the three horticultural substrates in agreement with the Van Genuchten-Mualem model, while the Valiantzas and Londra (2012) set of equations shows poor applicability to this particular value of the final pressure head.

\section{References}

Bibbiani C. 2002. An iterative procedure to estimate hydraulic characteristic of plant substrates from one-step outflow data. Agricoltura Mediterranea. 132:232-45.

Burdine N. 1953. Relative permeability calculation from pore size distribution data. Trans. Am. Inst. Min. Eng. 198:71-8.

Gardner WR. 1962. Note on the separation and solution of diffusion type equation. Soil Sci. Soc. Am. Proc. 26:404.

Johrar R.K., van Dam J.C., Bastiaansan W.G.M., Feddes R.A. 2004. Calibration of effective soil hydraulic parameters of heterogeneous soil profiles. J. Hydrol. 285:233-47.

Mualem Y. 1976. A new model for predicting the hydraulic conductivity of unsaturated porous media. Water Resour. Res. 12:513-22.

Passioura J.B. 1976. Determining soil water diffusivity from one-step outflow experiments. Aust. J. Soil Res. 15:1-8.

Schneider C.L., Attinger S., Delfs J.0., Hildebrandt A. 2009. Implementing small scale processes at the soil-plant interface - the role of root architectures for calculating root water uptake profiles. Hydrol. Earth Syst. Sci. Discuss. 6:4233-64.

Valiantzas J.D. 1989. A simple approximate equation to calculate diffusivities from one-step experiments. Soil Sci. Soc. Am. J. 53:342-9.

Valiantzas J.D., Kerkides P. 1990. A simple iterative method for the simultaneous determination of soil hydraulic properties from onestep outflow data. Water Resour. Res. 26:143-52.

Valiantzas J.D., Kerkides P., Poulovassilis A. 1988. An improvement to the one-step method for the determination of soil water diffusivities. Water Resour. Res. 24:1911-20.

Valiantzas J.D., Londra P.A. 2012. Simplified equations for the determination of the hydraulic properties of horticultural substrates by one-step outflow experiments. J. Plant Nutr. Soil Sci. 175:49-52.

Valiantzas J.D., Londra P.A., Sassalou A. 2007. Explicit formulae for soil water diffusivity using the one-step outflow technique. Soil Sci. Soc. Am. J. 71:1685-93.

Van Genuchten M.Th. 1980. A closed-form equation for predicting the hydraulic conductivity of unsaturated soils. Sci. Soc. Am. J. 44:892-8.

Van Genuchten M.Th., Leij F.J., Yates S.R. 1991. The RETC code for quantifying the hydraulic functions of unsaturated soils. U.S. Environmental Protection Agency - Center for Environmental research Information, Cincinnati, OH, USA. 